\title{
Biomassa de espécies florestais em área de caatinga arbórea
}

\author{
Aline Pereira das Virgens ${ }^{1}$, Patrícia Anjos Bittencourt Barreto-Garcia ${ }^{1}$, Alessandro de Paula ${ }^{1}$, Flávia Ferreira de Carvalho ${ }^{1}$, \\ Mariana de Aquino Aragão², Paulo Henrique Marques Monroe ${ }^{1}$
}

${ }^{1}$ Universidade Estadual do Sudoeste da Bahia, Estrada do Bem Querer, Km 4, CP. 95, CEP 45.031-900, Vitória da Conquista, BA, Brasil

${ }^{2}$ Universidade Federal do Espírito Santo, Av. Governador Lindemberg, 316, CEP 29550-000, Jerônimo Monteiro, ES, Brasil

*Autor correspondente:
patriciabarreto@uesb.edu.br

Termos para indexação:

Floresta nacional

Biomassa acima do solo

Carbono

Index terms:

National Forest

Above-ground biomass

Carbon

Histórico do artigo:

Recebido em 17/06/2017

Aprovado em 20/12/2017

Publicado em 29/12/2017

doi: 10.4336/2017.pfb.37.92.1465
Resumo - Estudos sobre quantificação de biomassa florestal na Caatinga ganham importância diante da escassez de informações relacionadas ao tema no bioma e, em particular, no estado da Bahia. Este estudo teve como objetivo avaliar os estoques de biomassa e sua distribuição nos componentes da parte aérea de espécies florestais de maior densidade populacional e o potencial de utilização do fator de expansão de biomassa (FEB) médio para obtenção de estimativas de biomassa aérea em área de Caatinga localizada na Floresta Nacional Contendas do Sincorá, BA. A biomassa foi quantificada pelo método destrutivo. Foram selecionadas e abatidas árvores representativas das nove espécies de maior densidade populacional, distribuídas em três classes diamétricas. As quantidades médias de biomassa total e carbono por árvore, considerando o conjunto das espécies amostradas, foram estimadas em $50,7 \mathrm{~kg} \operatorname{arv}^{-1} \mathrm{e} 25,3 \mathrm{~kg} \operatorname{arv}^{-1}$. Jatropha mollissima mostra-se dissimilar quanto à alocação de biomassa (galhos $>$ fuste $>$ folhas) em relação às demais espécies (fuste $>$ galhos $>$ folhas). Os maiores valores médios de biomassa individual foram verificados nas espécies Commiphora leptophloeos (171 kg arv $\left.{ }^{-1}\right)$, Coccoloba oblonga $\left(76 \mathrm{~kg} \mathrm{arv}^{-1}\right) \mathrm{e}$ Pseudobombax simplicifolium $\left(40 \mathrm{~kg} \mathrm{arv}^{-1}\right)$. O FEB médio obtido para o conjunto das espécies $(1,74)$ propiciou valores estimados próximos dos reais.

\section{Biomass of forest species in arboreal caatinga}

\begin{abstract}
Studies on the quantification of forest biomass in Caatinga are important due to the scarcity of information related to the theme in the biome and in particular in the state of Bahia, Brazil. The objective of this study was to evaluate the biomass stock and their distribution in the components of the aerial part of forest species with higher population density and the potential to use the biomass expansion factor (FEB) to obtain estimates of aerial biomass in the area of Caatinga, located in Contendas do Sincorá National Forest, BA. The biomass was quantified by destructive method. Representative trees of the nine species with the highest population density were selected felled, and distributed in three diametric classes. The average amount of total biomass and carbon per tree, considering all the species sampled, were estimated at $50.7 \mathrm{~kg}^{-1} \mathrm{ree}^{-1}$ and $25.3 \mathrm{~kg} \mathrm{tree}^{-1}$. Jatropha mollissima is dissimilar in relation to the biomass allocation (branches $>$ stem $>$ leaves) in relation to the other species (stem $>$ branches $>$ leaves). The highest values of individual biomass were verified in the species Commiphora leptophloeos (171 kg tre $\left.{ }^{-1}\right)$, Coccoloba oblonga $\left(76 \mathrm{~kg}^{-1} \mathrm{e}^{-1}\right)$ and Pseudobombax simplicifolium (40 kg tre $\left.\mathrm{e}^{-1}\right)$. The mean FEB obtained for all species (1.74) provided estimated values close to the real ones.
\end{abstract}




\section{Introdução}

O bioma Caatinga ocupa aproximadamente 11\% do território nacional, estando distribuído entre os estados do Piauí, Ceará, Rio Grande do Norte, Paraíba, Pernambuco, Sergipe, Alagoas, Bahia e Minas Gerais, o que corresponde a aproximadamente $844 \mathrm{mil} \mathrm{km}^{2}$ (Brasil, 2014). Apesar da sua grande importância, especialmente para a região Nordeste, a Caatinga vem sofrendo intenso processo de degradação, que tem avançado ao longo dos últimos anos (Sampaio, 2010). Tal processo tem como principal causa a remoção indiscriminada da vegetação do bioma (parcial ou total), que resulta na redução do estoque de biomassa vegetal e, consequentemente, da cobertura dos solos.

De acordo com o Ministério do Meio Ambiente (MMA) (Brasil, 2012), menos de 2\% do território da Caatinga pertence a unidades de conservação (UC), sendo considerado o bioma brasileiro menos protegido. Dentre as principais UC localizadas em áreas de Caatinga no Brasil, está a Floresta Nacional Contendas do Sincorá, BA, que, de acordo com o MMA (Silva et al., 2004), está inserida em uma área de importância biológica e prioritária para pesquisa científica, por possuir ambientes de exceção na Caatinga, prováveis endemismos e por ser insuficientemente conhecida.

A estimativa de biomassa é considerada uma importante ferramenta na avaliação e utilização de formações florestais, permitindo conhecer o potencial de produção de madeira para fins energéticos, especialmente quando se visa à utilização de todos os componentes da árvore (raiz, fuste e galhos). Além disso, estimativas de biomassa podem ser empregadas para diversos propósitos, como na avaliação da ciclagem de nutrientes, do sequestro de carbono (Behling et al., 2014) e, consequentemente, dos impactos que supostamente a retirada da biomassa possa vir a provocar no ambiente (Lima et al., 2016).

A quantificação de biomassa e carbono em florestas pode ser realizada por métodos diretos e indiretos. Os métodos diretos são aqueles que proporcionam a obtenção da medida real, como a pesagem em balança dos compartimentos arbóreos, executada diretamente em campo (Ratuchne et al., 2016). O método indireto consiste na utilização de variáveis de fácil medição para obtenção de relações quantitativas e matemáticas, como os fatores de expansão de biomassa e modelos alométricos, que permitem estimar a biomassa, dispensando a necessidade do abate de árvores (Silveira et al., 2008).

O FEB possibilita a conversão de estimativas de volume em biomassa florestal (Silveira et al., 2008). Esse fator geralmente é resultante da relação entre a biomassa total e a biomassa do fuste (Schikowski et al., 2015). Com base nos valores do FEB, é possível modelar estimativas de quantidade de biomassa em diferentes espécies florestais. De acordo com o Good Practice Guidance do IPCC (Intergovernmental Panel on Climate Change, 2003), a biomassa total pode ser expressa por uma relação direta entre o volume comercial, densidade básica da madeira e o FEB.

Estudos sobre quantificação ou estimação de biomassa arbórea ainda são escassos em condições de Caatinga de uma forma geral e, em particular, em sua fisionomia arbórea. Diante disso, este estudo teve como objetivo: avaliar os estoques e distribuição de biomassa da parte aérea de espécies florestais de maior densidade populacional e o potencial de utilização do FEB médio para estimação de biomassa em área de Caatinga arbórea, localizada na Floresta Nacional Contendas do Sincorá, BA.

\section{Material e métodos}

\section{Caracterização da área}

O estudo foi conduzido na (FLONA) Contendas do Sincorá, localizada no Município de Contendas do Sincorá, BA. A FLONA possui área total de cerca de 11 mil ha, tendo sua sede situada nas coordenadas geográficas $13^{\circ} 45^{\prime} \mathrm{N}$ e $41^{\circ} 02^{\prime} \mathrm{W}$. Sua vegetação predominante é classificada como Caatinga arbórea e encontra-se em estágio sucessional tardio, tendo em vista que não sofria intervenção antrópica desde 1997 (ano do último registro de exploração, corte seletivo em execução de plano de manejo) (Brasil, 2006).

O clima da região é caracterizado como semi-árido quente (tipo BSwh), de acordo com a classificação de Köppen), com estação chuvosa no período de novembro a janeiro. A precipitação varia de $500 \mathrm{~mm}$ a $1.000 \mathrm{~mm}$ anuais, a temperatura entre $21^{\circ} \mathrm{C}$ e $28{ }^{\circ} \mathrm{C}$ e a umidade relativa entre $60 \%$ e $70 \%$.

\section{Quantificação da biomassa e volume}

A amostragem das árvores para a quantificação da biomassa foi realizada pelo método direto, no período 
de junho a julho de 2015. Foram lançadas aleatoriamente 48 parcelas de $20 \mathrm{~m}$ x $20 \mathrm{~m}\left(400 \mathrm{~m}^{2}\right)$, onde foi realizada a medição de diâmetro a $1,30 \mathrm{~m}$ do solo (DAP) de todos os indivíduos arbóreos, tendo como nível de inclusão $\mathrm{DAP} \geq 5,0 \mathrm{~cm}$. Em decorrência de grande parte das espécies possuírem crescimento perfilhado, ou seja, uma mesma árvore apresentar vários fustes, foram medidos os DAP de todos os fustes originados abaixo de $1,30 \mathrm{~m}$. As medidas de DAP dos fustes foram agrupadas em três classes de diâmetro com amplitude correspondendo a $8 \mathrm{~cm}$, conforme Tabela 1 .

Tabela 1. Distribuição diamétrica dos fustes de árvores da Floresta Nacional de Contendas do Sincorá.

\begin{tabular}{cccc}
\hline \multicolumn{2}{c}{$\begin{array}{c}\text { Classes de DAP* } \\
(\mathbf{c m})\end{array}$} & $\begin{array}{c}\text { Centro de classe } \\
(\mathbf{c m})\end{array}$ & $\mathbf{f i}$ \\
\hline I & $5,00-12,99$ & 8,95 & 1.234 \\
II & $13,00-20,99$ & 17,05 & 96 \\
III & $21,00-28,99$ & 25,05 & 25 \\
\hline
\end{tabular}

*DAP $=$ diâmetro a $1,3 \mathrm{~m}$ do nível do solo; $f \mathrm{i}=$ frequência de indivíduos arbóreos com DAP $\geq 5 \mathrm{~cm}$ em um total de 48 parcelas de $400 \mathrm{~m}^{2}$.

Ainda em campo, os indivíduos arbóreos tiveram suas espécies reconhecidas pelo nome vulgar, sendo retirada amostra para identificação botânica. A identificação das espécies foi realizada no laboratório de Ecologia e Proteção Florestal da Universidade Estadual do Sudoeste da Bahia (UESB), com consulta a bibliografia especializada e acesso a herbário virtual (The Field Museum, 2017; Trópicos, 2017). Para a determinação da biomassa, foram selecionadas e abatidas 25 árvores das nove espécies que apresentaram maior densidade populacional, distribuídas em três classes de DAP (Tabela 1).

Cada árvore-amostra foi medida para obtenção do DAP, altura total e volume, por meio de cubagem rigorosa pelo método de Smalian. Os diâmetros ao longo do fuste foram medidos nas posições de $0,1 \mathrm{~m}, 0,3 \mathrm{~m}$, $0,5 \mathrm{~m}, 0,7 \mathrm{~m}, 1,0 \mathrm{~m}, 1,3 \mathrm{~m}, 2 \mathrm{~m}$ do nível do solo e a partir desse ponto as seções foram medidas a cada metro até a posição do diâmetro mínimo de $3 \mathrm{~cm}$, medindo-se também o comprimento da ponta.

Após cubagem, cada árvore-amostra foi fracionada nos compartimentos folhas, galhos (ramificações com diâmetro $<5 \mathrm{~cm}$ ) e fuste, que foram pesados em balança mecânica, com capacidade de $150 \mathrm{~kg}$ e precisão de 50 g, para determinação da biomassa verde. Foram separadas sub-amostras de cada compartimento, que foram conduzidas ao laboratório e tiveram suas massas úmida e seca (após secagem em estufa de circulação forçada de ar, a $65^{\circ} \mathrm{C}$ ) determinadas com auxílio de uma balança de precisão $(0,01 \mathrm{~g})$. A biomassa seca de cada um dos componentes das árvores foi estimada com base na relação entre massa seca e massa úmida da amostra (Soares et al., 2011).

Os valores de biomassa seca das árvores-amostra em conjunto foram projetados para ha, considerando a biomassa média por classe de DAP multiplicada pela frequência da classe nas parcelas experimentais. A quantidade de carbono estocado na biomassa foi estimada por meio da multiplicação da massa seca pelo fator 0,5 , em conformidade com o proposto pelo IPCC (Intergovernmental Panel on Climate Change, 2006), que considera que a biomassa seca contém aproximadamente $50 \%$ de carbono.

\section{Fator de expansão de biomassa}

Para o cálculo do fator de expansão de biomassa (FEB) das árvores, foi utilizada a equação 1 , recomendada pelo IPCC (Intergovernmental Panel on Climate Change, 2006). A partir da média aritmética dos valores individuais de FEB, obteve-se o FEB médio do povoamento.

$$
\mathrm{FEB}=\frac{\mathrm{m}_{\text {copa }}+\mathrm{m}_{\text {fuste }}}{\mathrm{m}_{\text {fuste }}}=\frac{\mathrm{m}_{\text {aérea }}}{\mathrm{m}_{\text {fuste }}}
$$

Em que: $\mathrm{FEB}$ = fator de expansão da biomassa (adimensional); $\mathrm{m}_{\text {copa }}=$ massa seca da copa $(\mathrm{kg}) ; \mathrm{m}_{\text {fuste }}=$ peso seco do fuste $(\mathrm{kg}) ; \mathrm{m}_{\text {aérea }}=$ massa seca do fuste + massa seca da copa da árvore $(\mathrm{kg})$.

\section{Análises e validação dos dados}

Os dados de alocação de biomassa nos componentes folhas, galhos e fuste das espécies foram submetidos à análise de agrupamento (cluster), empregando-se o software XLSTAT ${ }^{\circledR}$, com método hierárquico e distância euclidiana, que teve propósito de agrupar as espécies segundo suas similaridades.

Com finalidade de avaliar como o FEB médio comporta-se na estimativa de dados independentes daqueles usados para sua obtenção, foram mensuradas cinco árvores adicionais, não utilizadas no conjunto inicial dos dados. A validação consistiu em estimar as biomassas dessas árvores (multiplicando-se o FEB médio pelo volume individual do fuste de cada árvore e por sua respectiva densidade, conforme equação 2) e comparar estas estimativas com os valores reais de biomassa. Para tanto, foi aplicado o teste t para dados 
pareados $(\alpha=0,05)$, utilizando-se o programa estatístico SAEG ${ }^{\circledR}$ v.9.1. Além disso, foi considerado o erro médio em porcentagem, calculado pela diferença entre o valor real e o valor estimado, como empregado por Kohler et al. (2013).

$$
B=V \times D \times F E B
$$

Em que: $\mathrm{B}=$ biomassa $(\mathrm{kg}) ; \mathrm{V}=$ volume $\left(\mathrm{m}^{3}\right) ; \mathrm{D}=$ massa específica básica da madeira $\left(\mathrm{kg} \mathrm{m}^{-3}\right) ; \mathrm{FEB}=$ fator de expansão de biomassa.

Para avaliar a possibilidade de modelagem da variável FEB por meio de relações matemáticas, foram estimadas as correlações lineares de Pearson entre FEB, DAP e altura.

\section{Resultados}

\section{Estoques de biomassa}

O total de biomassa seca foi estimado em 29,2 $\mathrm{Mg} \mathrm{ha}^{-1}\left(50,71 \mathrm{~kg} \mathrm{arv}^{-1}\right)$ (Tabela 2), o que corresponde a um estoque de carbono de cerca de $15 \mathrm{Mg} \mathrm{ha}^{-1}$. As árvores apresentaram, em média, $25,35 \mathrm{~kg}$ de $\mathrm{C}$.
A distribuição da biomassa nos diferentes compartimentos das árvores mostrou maior participação do fuste, que representou, em média, $73,9 \%$ da parte aérea, seguido dos galhos $(25,5 \%)$ e folhas $(0,5 \%)$ (Tabela 2).

Ao quantificar a biomassa por espécie, observouse valores entre $4 \mathrm{~kg}$ e $310 \mathrm{~kg}$ (Tabela 3). Dentre as nove espécies estudadas, Commiphora leptophloeos apresentou maior média de biomassa total (171 kg arv $\mathrm{k}^{-1}$ ), seguida por Coccoloba oblonga $\left(76 \mathrm{~kg} \mathrm{arv}^{-1}\right)$ e por Pseudobombax simplicifolium $\left(40 \mathrm{~kg} \mathrm{arv}^{-1}\right)$. A menor média de biomassa foi observada para a espécie Manihot glaziovii $\left(4,3 \mathrm{~kg} \mathrm{arv}^{-1}\right)$.

A biomassa foliar das espécies variou de $0,01 \mathrm{~kg} \mathrm{arv}^{-1}$ a $2,43 \mathrm{~kg} \mathrm{arv}^{-1}$, representando proporções entre 0 e $5 \%$ do total de biomassa aérea (Tabela 3). Maior quantidade de biomassa foliar foi encontrada para Coccoloba oblonga, enquanto maiores quantidades de galhos e fuste foram observadas em Commiphora leptophloeos. Por sua vez, a espécie Jatropha molissima foi a espécie que apresentou menor biomassa foliar e a maior participação dos galhos $(69,9 \%)$ (Tabela 3).

Tabela 2. Biomassa e carbono médios por indivíduo em área de Caatinga arbórea localizada na Floresta Nacional de Contendas do Sincorá, BA.

\begin{tabular}{|c|c|c|c|c|c|c|c|}
\hline \multirow{2}{*}{ Compartimento } & \multicolumn{5}{|c|}{ Biomassa $\left(k \operatorname{arv}^{-1}\right)$} & \multirow{2}{*}{$\begin{array}{c}\text { Biomassa } \\
\%\end{array}$} & \multirow{2}{*}{$\begin{array}{c}\text { Carbono } \\
\mathrm{kg} \mathrm{arv}^{-1}\end{array}$} \\
\hline & Média & $\mathbf{S}$ & EP & Máximo & Mínimo & & \\
\hline Folhas & 0,27 & 0,49 & 0,10 & 2,39 & 0,00 & 0,53 & 0,14 \\
\hline Galhos & 12,94 & 13,33 & 2,67 & 48,52 & 0,15 & 25,52 & 6,47 \\
\hline Fuste & 37,49 & 62,04 & 12,41 & 277,26 & 2,56 & 73,94 & 18,75 \\
\hline Total & 50,71 & 71,88 & 14,38 & 309,90 & 4,33 & 100,00 & 25,35 \\
\hline
\end{tabular}

Fuste $=$ fuste com casca; $\mathrm{S}=$ desvio padrão; $\mathrm{EP}=$ erro padrão

Tabela 3. Biomassa média por espécie, por compartimento $\left(\mathrm{kg} \operatorname{arv}^{-1} \mathrm{e} \%\right)$ em área de Caatinga arbórea localizada na Floresta Nacional de Contendas do Sincorá, BA.

\begin{tabular}{|c|c|c|c|c|c|c|c|c|}
\hline \multirow{3}{*}{ Família } & \multirow{3}{*}{ Espécie } & \multicolumn{7}{|c|}{ Biomassa } \\
\hline & & \multicolumn{2}{|c|}{ Folhas } & \multicolumn{2}{|c|}{ Galhos } & \multicolumn{2}{|c|}{ Fuste } & \multirow{2}{*}{$\begin{array}{c}\text { Total } \\
\text { kg arv } \\
\end{array}$} \\
\hline & & $\mathrm{kg} \mathrm{arv}^{-1}$ & $\%$ & $\mathrm{~kg} \mathrm{arv}^{-1}$ & $\%$ & $\mathrm{~kg} \mathrm{arv}^{-1}$ & $\%$ & \\
\hline Apocynaceae & Aspidosperma pyrifolium Mart. & 0,47 & 1,4 & 15,50 & 44,9 & 18,55 & 53,7 & 34,51 \\
\hline Boraginaceae & Patagonula bahiensis Moric. & 0,27 & 1,6 & 3,66 & 22,6 & 12,29 & 75,8 & 16,21 \\
\hline Burseraceae & Commiphora leptophloeos (Mart.) J. B. Gillett & 0,02 & 0,0 & 35,96 & 21,0 & 134,98 & 79,0 & 170,95 \\
\hline Euphorbiaceae & Croton sp. & 0,09 & 0,2 & 4,34 & 11,0 & 35,01 & 88,8 & 39,44 \\
\hline Euphorbiaceae & Jatropha molissima (Pohl) Baill. & 0,01 & 0,1 & 7,16 & 69,9 & 3,08 & 30,0 & 10,24 \\
\hline Euphorbiaceae & Manihot glaziovii Müll. Arg & 0,03 & 0,7 & 1,73 & 40,1 & 2,56 & 59,2 & 4,33 \\
\hline Fabaceae & Chloroleucon foliolosum (Benth.) G. P. Lewis & 0,74 & 4,7 & 6,19 & 39,0 & 8,94 & 56,3 & 15,86 \\
\hline Malvaceae & Pseudobombax simplicifolium A. Robyns & 0,02 & 0,0 & 8,40 & 21,1 & 31,35 & 78,9 & 39,75 \\
\hline Polygonaceae & Coccoloba oblonga Lindau & 2,39 & 3,1 & 19,92 & 26,2 & 53,65 & 70,7 & 75,96 \\
\hline
\end{tabular}

Fuste $\mathrm{c} / \mathrm{c}=$ fuste com casca. Médias de 25 árvores/espécies. 
O dendrograma de similaridade das espécies, obtido com base na distribuição de biomassa nos diferentes compartimentos das árvores, mostrou a formação de três grupos principais (Figura 1); um composto por Jatropha molissima (sp6), outro formado pelas espécies Commiphora leptophloeos (sp4), Croton sp. (sp5) e Pseudobombax simplicifolium (sp9), e o terceiro grupo formado pelas demais espécies (Figura 1).

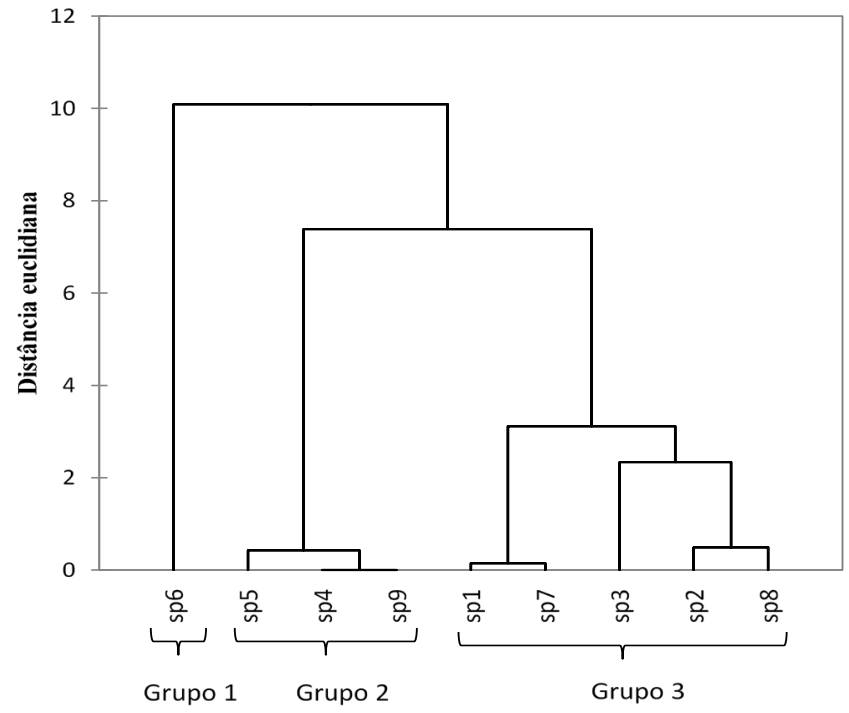

$\mathrm{sp} 1$ = Aspidosperma pyrifolium Mart, $\mathrm{sp} 2$ = Coccoloba oblonga Lindau, sp3 = Chloreleucon foliolosum (Benth.) G. P. Lewis, sp4 = Commiphora leptophloeos (Mart.) J. B. Gillett., sp5=Croton sp., sp6 = Jatropha mollissima (Pohl.) Baill., sp7 = Manihot graziovii Müll. Arg., sp8 = Patagonula bahiensis Moric., sp9 = Pseudobombax simplicifolium A. Robyns.

Figura 1. Dendrograma de dissimilaridade das diferentes espécies amostradas em Contendas do Sincorá,BA. Nota $=$ em relação aos atributos biológicos.

Quando se avaliou a média de biomassa total por classe diamétrica, foram constatados valores variando entre 18,9 kg arv ${ }^{-1}$ (classe I) e 172,2 $\mathrm{kg} \mathrm{arv}^{-1}$ (classe III) (Tabela 4). Para os componentes galhos e fuste, verificou-se incremento da biomassa com aumento do diâmetro. Para a fração folhas, foi encontrada maior média na classe II e menor na classe III, embora esta última tenha apresentado o maior estoque de biomassa total.

Tabela 4. Biomassa individual média por classe diamétrica de espécies amostradas em Contendas do Sincorá,BA.

\begin{tabular}{ccccc}
\hline \multirow{2}{*}{$\begin{array}{c}\text { Classe } \\
\text { Diamétrica }\end{array}$} & \multicolumn{4}{c}{ Biomassa $\left(\mathbf{k g ~ a r v}^{-1}\right)$} \\
\cline { 2 - 5 } & Folhas & Galhos & Fuste c/c & Total \\
\hline I & 0,25 & 6,45 & 12,17 & 18,87 \\
II & 0,56 & 22,11 & 32,68 & 55,36 \\
III & 0,00 & 27,44 & 144,80 & 172,24 \\
\hline
\end{tabular}

\section{Fator de expansão de biomassa}

A média do fator de expansão de biomassa (FEB) para as condições estudadas foi de $1,74 \pm 0,57$, com valor mínimo de 1,02 e máximo de 4,45. Ao analisar as médias de FEB por espécie, observou-se menor valor para Croton sp. $(1,13)$ e maior para Jatropha mollissima $(3,33)$.

As diferenças entre as estimativas de biomassa obtidas pelo FEB médio, considerando o conjunto de espécies e os seus respectivos valores reais, quando analisadas pelo teste $\mathrm{t}$ pareado, foram consideradas não significativas $(\mathrm{p}=0,8711 ; \alpha=0,05)$. Por outro lado, a análise da correlação de Pearson do (FEB) com o DAP e a altura demonstrou baixo grau de associação entre variáveis e, com isso, que o emprego destas não resultaria em ajustes satisfatórios para modelagem da variável FEB.

\section{Discussão}

\section{Estoques de biomassa}

O total de biomassa seca observado $\left(29,2 \mathrm{Mg} \mathrm{ha}^{-1}\right)$ é próximo ao relatado por Amorim et al. (2005) para vegetação arbustivo-arbórea de Caatinga no Seridó, $\mathrm{RN}$ (25 $\left.\mathrm{Mg} \mathrm{ha}^{-1}\right)$.

A maior contribuição do fuste é explicada por este compartimento ser o mais representativo em armazenamento de carbono, já que constitui o principal reservatório da planta (Kuzyarov \& Domanski, 2000). A distribuição da biomassa arbórea (fuste $>$ galhos $>$ folhas) mostra padrão semelhante ao encontrado por Cunha et al. (2009) em áreas de Floresta Atlântica (fuste $=61 \%$, galho $=21 \%$ e folha $=5 \%$ ). No entanto, Alves (2012), quantificando a biomassa arbórea de Caatinga arbustiva no município de Floresta, PE, verificaram alocação de biomassa na seguinte ordem: galhos $>$ fuste $>$ folhas. Diferenças no estoque de biomassa podem estar relacionadas ao estágio sucessional da floresta, que promove variação das espécies quanto ao acúmulo e distribuição de biomassa, número de perfilhos ou ainda à grande variação espacial e sazonal verificada nas áreas de abrangência do bioma Caatinga, principalmente em função da precipitação pluviométrica e distribuição irregular das chuvas (Lima Júnior et al., 2014).

Por outro lado, a baixa participação das folhas observada para todas as espécies estudadas (0 e 5\% do total de biomassa aérea), pode ser atribuída ao comportamento caducifólio das árvores, que é comum em grande parte das espécies da Caatinga, perdendo 
suas folhas no período de seca, como mecanismo natural para evitar a perda de água por transpiração (Alves, 2012). Esses resultados são corroborados por Silva et al. (2008) que, estudando espécies da Caatinga nos estados do Pernambuco e Bahia, observaram que o compartimento folhas representava proporção máxima de 5\% da biomassa total. Drumond et al. (2008) e Alves (2012), em Caatinga no estado do Pernambuco, também observaram menor contribuição das folhas na composição da biomassa total, com proporções de 7,5 a $13 \%$.

O acúmulo de biomassa total apresentou grande variabilidade entre as árvores, o que resultou em elevado desvio padrão da média $\left( \pm 71,88 \mathrm{~kg} \mathrm{arv}^{-1}\right)$. Silva et al. (2008), estudando diferentes espécies da Caatinga, também observaram ampla variação na biomassa das árvores, atingindo valores entre 4 e 454 $\mathrm{kg}$. Comportamento semelhante foi observado por Vogel et al. (2006) em uma Floresta Estacional Decidual em Itaara, RS, que atribuíram o resultado observado a diversidade de espécies, que propicia indivíduos com densidades de madeira e dimensões variadas.

$\mathrm{Na}$ análise de agrupamento, a separação da espécie Jatropha molissima (sp6) em relação às demais, que foram agrupadas em outros dois grupos, denota um padrão diferenciado, com maior participação de galhos $(69,9 \%)$, seguida do fuste $(30,0 \%)$ e das folhas $(0,1 \%)$ (Tabela 3). Tal diferenciação pode estar relacionada às características da espécie, como grande quantidade de perfilhos e bifurcações, o que reduziu a massa do fuste em relação à massa total de galhos, e o seu comportamento caducifólio, com deciduidade total durante os meses de maio a julho (Neves et al., 2010). O comportamento caducifólio de J. molissima também foi observado por Lima \& Rodal (2010).

A separação do grupo 2 evidencia similaridade entre as espécies que o compõe quanto à alocação de biomassa (Figura 1). Commiphora leptophloeos (sp4), Croton sp. (sp5) e Pseudobombax simplicifolium (sp9) foram as espécies que apresentaram as maiores proporções de biomassa alocada no fuste e, ao mesmo tempo, as menores proporções nas folhas. Cabral et al. (2013), estimando a biomassa de diferentes espécies de Caatinga em estágio sucessional tardio, observaram que a espécie Commiphora leptophloeos apresentou a segunda maior biomassa aérea dentre 21 espécies amostradas.

As espécies que compõem o grupo 3 também possuem característica semelhante de distribuição de biomassa, apresentando, de forma geral, as maiores alocações de folhas $\left(3,9 \mathrm{~kg}^{2}\right.$ rv $\left.^{-1}\right)$ em comparação com as demais espécies $\left(0,13 \mathrm{~kg}\right.$ árv $\left.^{-1}\right)$. Apesar disso, a distribuição dos estoques nos compartimentos destas espécies seguiu a mesma ordem das espécies do grupo 2: fuste $>$ galhos $>$ folhas, representando cerca de $74 \%, 25 \%$ e $1 \%$ da biomassa total, respectivamente.

O valor médio do fator de expansão da biomasa (FEB) observado neste estudo $(1,7)$ é próximo ao reportado por Segura \& Kanninem $(2005)(1,6)$, para 19 indivíduos de diferentes espécies de uma Floresta Tropical Úmida na Costa Rica.

A ampla variação de FEB entre espécies sugere que a utilização de valores default de FEB, como os sugeridos pelo IPCC (Intergovernmental Panel on Climate Change, 2006), poderia acarretar em erros implícitos nas estimativas de biomassa. No entanto, não houve diferenças significativas entre os resultados de biomassa estimada pelo FEB médio e seus valores reais, com aproximadamente $4,5 \%$ de erro médio associado às estimativas. Silveira (2010), estimando a biomassa aérea por diferentes métodos em Floresta Ombrófila Densa, observaram que o FEB médio propiciou estimativas de biomassa próximas àquelas obtidas por meio do FEB por espécie, com diferença de apenas 2,7\%. Para Sanquetta et al. (2014), devido à sua simplicidade e aplicação imediata, o FEB representa importante alternativa para estimar a biomassa e, por consequência, o carbono das árvores.

\section{Conclusões}

Dentre as nove espécies com maior densidade populacional nas condições de Caatinga estudadas, Commiphora leptophloeos destaca-se por apresentar maior estoque de biomassa, seguida de Coccoloba oblonga e Pseudobombax simplicifolium. Por outro lado, estas duas últimas espécies apresentam menor biomassa foliar.

Jatropha mollissima mostra-se dissimilar quanto à alocação de biomassa (galhos $>$ fuste $>$ folhas) em relação às demais espécies (fuste $>$ galhos $>$ folhas).

Os valores do fator de expansão da biomassa (FEB ) apresentam forte variação entre as espécies estudadas. No entanto, o FEB médio obtido para o conjunto das espécies $(1,74)$ pode ser utilizado para estimação de biomassa, uma vez que propiciou valores estimados próximos dos reais. 


\section{Referências}

Alves, A. R. Quantificação de biomassa e ciclagem de nutrientes em áreas de vegetação de caatinga no município de Floresta, Pernambuco. Sapiência, v. 1, p. 10, 2012.

Amorim, I. et al. Flora e estrutura da vegetação arbustivo-arbórea de uma área de caatinga do Seridó. Acta Botanica Brasilica, v. 19, n. 3, p. 615-623, 2005. DOI: 10.1590/S0102-33062005000300023.

Behling, A. et al. Teores de carbono orgânico de três espécies arbóreas em diferentes espaçamentos. Pesquisa Florestal Brasileira, v. 34, p. 13-19, 2014. DOI: 10.4336/2014.pfb.34.77.562.

Brasil. Ministério do Meio Ambiente. Caatinga. Brasília, DF, 2014. Disponível em: <www.mma.gov.br/biomas/caatinga >. Acesso em: 23 jul. 2014

Brasil. Ministério do Meio Ambiente. Cadastro Nacional de Unidades de Conservação. Unidades de conservação por bioma. Brasília, DF, 2012. Disponível em: <www.mma.gov.br/cadastro_uc>. Acesso em: 2 out. 2017.

Brasil. Ministério do Meio Ambiente. Plano de manejo da Floresta Nacional Contendas do Sincorá. volume I: informações gerais sobre a floresta nacional. 2006. Disponível em: $<$ http://www.icmbio.gov. br/portal/images/stories/imgs-unidades-coservacao/contendas_do_ sincora1.pdf>. Acesso em: 23 jul. 2014.

Cabral, G. A. L. et al. Estrutura espacial e biomassa da parte aérea em diferentes estádios sucessionais de Caatinga, em Santa Terezinha. Revista Brasileira de Gografia Física, v. 6, n. 03, p. 566-574, 2013.

Cunha, G. M. et al. Biomassa e estoque de carbono e nutrientes em Florestas Montanas da Mata Atlântica na região Norte do Estado do Rio de Janeiro. Revista Brasileira de Ciência do Solo, v. 33, p. 1175-1185, 2009. DOI: 10.1590/S0100-06832009000500011.

Drumond, M. A. et al. Produção e distribuição de biomassa de espécies arbóreas no semi-árido brasileiro. Revista Árvore, v. 32, n. 4, p. 665-669, 2008. DOI: 10.1590/S0100-67622008000400007.

Intergovernmental Panel on Climate Change. Good practice guidance for land use, land-use change and forestry. Hayama: Institute for Global Environmental Strategies, 2003. Disponível em: $<$ http://www.ipcc.ch>. Acesso em: 28 ago. 2017.

Intergovernmental Panel on Climate Change. Guidelines for national greenhouse gas inventories: agriculture, forestry and other land use. [S.1.]: Institute for Global Environmental Strategies, 2006. v. 2. p. 2-59. Disponível em: <http://www.ipcc.ch>. Acesso em: 28 ago. 2017.

Kohler, S. V. et al. Modelos de afilamento para Pinus taeda por classes de idade. Floresta e Ambiente, v. 20, n. 4, p. 470-479, 2013. DOI: 10.5902/1980509825120.

Kuzyarov, Y. \& Domanski, G. Carbon input by plants into the soil: review. Jornaul of Plant Nutrition and Soil Science, v. 163, p. 421-431, 2000. DOI: 10.1002/1522-2624(200008)163.

Lima, A. L. A. \& Rodal, M. J. N. Phenology and wood density of plants growing in the semi-arid region of northeastern Brazil. Journal of Arid Environments, v. 74, p. 1363-1373, 2010. DOI: 10.1016/j. jaridenv.2010.05.009.
Lima Júnior, C. et al. Estimativa de biomassa lenhosa da caatinga com uso de equações alométricas e índice de vegetação. Scientia Forestalis, v. 42, n. 102, p. 289-298, 2014.

Lima, M. C. D. et al. Biomass and carbon stock from Pinus caribaea var. hondurensis under homogenous stands in southwest Bahia, Brazil. Ciência Rural, v. 46, p. 957-962, 2016. DOI: 10.1590/01038478 cr20150493.

Neves, E. L. et al. Comportamento fenológico de três espécies de Jatropha (Euphorbiaceae) da Caatinga, semi-árido do Brasil. Revista Brasileira Botânica, v. 33, n. 1, p. 155-166, 2010. DOI: 10.1590/ S0100-84042010000100014.

Ratuchne, L. C. et al. Estado da arte na quantificação de biomassa em raízes de formações florestais. Floresta e Ambiente, v. 23, n. 3 , 2016. DOI: $10.1590 / 2179-8087.131515$.

Sampaio, E. V. S. B. Características e potencialidades. In: Gariglio, M. A. et al. (Ed.). Uso sustentável e conservação dos recursos florestais da Caatinga. Brasília, DF: Ministério do Meio Ambiente, Serviço Florestal Brasileiro, 2010. p. 29-48.

Sanquetta, C. R. et al. Estimativa de carbono individual para Araucaria angustifolia. Pesquisa Agropecuária Tropical, v. 44, p. 1-8, 2014. DOI: 10.1590/S1983-40632014000100006.

Schikowski, A. B. et al. Análise e ajuste do fator de expansão de biomassa e razão raízes-parte aérea para álamo. Enciclopédia Biosfera, v. 11, p. 107-119, 2015.

Segura, M. \& Kanninen, M. Allometric models for tree volume and total aboveground biomass in a tropical humid forest in Costa Rica. Biotropica, v. 37, n. 1, p. 2-8, 2005.

Silva, G. C. \& Sampaio, E. V. S. B. Biomassa de partes aéreas em plantas da Caatinga. Revista Árvore, v. 32, n. 3, p. 567-575, 2008. DOI: $10.1590 / \mathrm{S} 0100-67622008000300017$.

SILVA, J. M. C. da et al. (Org.). Biodiversidade da caatinga: áreas e ações prioritárias para a conservação. Brasília, DF: Ministério do Meio Ambiente: Universidade Federal de Pernambuco, 2004. Disponível em: <http://ainfo.cnptia.embrapa.br/digital/bitstream/ item/18306/1/Caatinga.pdf $>$. Acesso em: 26 ago. 2016.

Silveira, P. Estimativa da biomassa e carbono acima do solo em um fragmento de Floresta Ombrófila Densa utilizando o método da derivação do volume comercial. Floresta, v. 40, n. 4, p. 789-800, 2010.

Silveira, P. et al. O estado da arte na estimativa de biomassa e carbono em formações florestais. Floresta, v. 38, n. 1, p. 185-206, 2008.

Soares, C. P. B. et al. Dendrometria e inventário florestal. 2. ed. Viçosa, MG: Ed. da UFV, 2011. 270 p.

The Field Museum. Disponível em: $<$ http://fm1.fieldmuseum.org>. Acesso em: 2 out. 2017.

Trópicos. Disponível em: <www.tropicos.org>. Acesso em: 2 out. 2017.

Vogel, H. L. M. et al. Quantificação da biomassa em uma floresta estacional decidual em Itaara, Ciência Florestal, v. 16, n. 4, p. 419425, 2006. DOI: 10.5902/198050981923. 
